\title{
Subjetividade: Um Diálogo Interdisciplinar
}

\author{
Miriam A. Graciano de Souza Pan \\ João Henrique Rossler \\ Norma da Luz Ferrarini \\ Luciana Albanesse Valore \\ Sidney Nilton de Oliveira \\ Universidade Federal do Paraná
}

\begin{abstract}
RESUMO
O termo subjetividade tem-se difundido amplamente no campo das ciências humanas e sociais, no entanto, de forma bastante genérica, sem as devidas clareza e precisão conceituais. Na Psicologia, em suas diversas abordagens teórico-metodológicas, por exemplo, tem se tornado apenas mais um jargão sem qualquer significação, o que, por sua vez, contribui para ofuscar tanto suas especificidades como possíveis aproximações teórico-conceituais. Nesse sentido, o presente artigo se propõe a analisar o conceito de subjetividade à luz de distintas perspectivas teóricas do campo da Psicologia. Mais especificamente, a partir de uma análise filosófica do sujeito e da linguagem, da Psicologia Sóciohistórica e de um enfoque discursivo da Psicologia Institucional. Dentre as especificidades e divergências existentes, tal análise ampliada torna possível ressaltar um elemento comum e fundamental entre aportes teórico-metodológicos distintos. A saber, o entendimento da subjetividade como sendo, simultaneamente, produzida por e (re)produtora de relações históricas, sociais e simbólicas; ou seja, como produto de processos educativos (formativos) datados e situados em uma trama complexa, cujas especificidades configuram processos sociais contraditórios que, assim, determinam e/ou recompõem processos objetivos e subjetivos de assujeitamento-resistência ou, em outras palavras, de alienação-emancipação.
\end{abstract}

Palavras-chave: subjetividade; discurso; psicologia sócio-histórica; psicologia institucional.

\begin{abstract}
Subjectivity: an Interdisciplinary Dialogue

The term subjectivity has widely used in the humanities and social sciences, however, in a quite generic sense, without the necessary conceptual clarity and precision. In psychology, in its various theoretical and methodological approaches, for example, subjectivity has become just another jargon without any significance, thereby obfuscating the field's own specific theoretical and conceptual approaches. In that sense, this article aims to analyze the concept of subjectivity in the light of different theoretical perspectives of the field of psychology. Specifically, it considers the philosophical analysis of the subject and language, the perspective of social-historical psychology and the discursive approach of institutional psychology. Among the specificities and divergences, this expanded analysis highlights a common element of fundamental, theoretical-methodological distinction. Namely, subjectivity is simultaneously produced by, and (re)productive of, the historical, social and symbolic contents as a product of the educational or formative process, historically embedded and situated in a complex space that shapes certain contradictory social processes, which then determine and / or reassemble objective and subjective processes of submission-resistance or, in other words, alienation-emancipation.
\end{abstract}

Keywords: subjectivity; discourse; social-historical psychology; institutional psychology.

Analisar o conceito de subjetividade é por si só um grande desafio; tomá-lo de modo interdisciplinar pode parecer mais complexo ainda, porém inevitável. Os estudos contemporâneos sobre a subjetividade não se circunscrevem mais a campos específicos, tampouco a tradições teóricas determinadas. O início deste século traz a marca da questão do sujeito produtor/produzido na/pela sociedade e na/pela ciência moderna, transgredindo os modos clássicos de compreendê-lo como fundamento, substância, centro, essência. A subjetividade passa a ser pensada de modo situado, ou seja, num tempo determinado por grandes transformações 
no campo da política, da economia, das ciências, tecnologias e artes, colocando problematizações para a teorização do sujeito e ao modo de tratá-lo, como sujeito da consciência ou sujeito do cogito, uno, homogêneo e soberano, bem como ao modo de recuperálo para análise científica.

Na sociedade agrária da Idade Média, a individualidade era praticamente predefinida em função de eventos biográficos casuais como a comunidade ou o grupo em que se nascia, os laços sanguíneos, filiação, idade etc. e as relações sociais eram estabelecidas, essencialmente, em função de tradições, obrigações e lealdade. $\mathrm{O}$ indivíduo sujeitava-se a uma ordem rígida superior, a papéis predefinidos, ao que a comunidade imediata lhe impunha, limitando-lhe as possibilidades de construção de sua própria identidade. Assim, como o universo medieval era geocêntrico, finito, esférico, hierarquizado, ordenado, a vida do homem também era regrada por uma ordem divina, por tradições e por uma hierarquia social preestabelecida. O que produzia, então, certa estabilidade, rigidez e permanência no cotidiano da sociedade e na vida concreta dos indivíduos, estreitando-lhes as possibilidades de singularização, como também nas ideias aí produzidas, ou seja, nas explicações teóricas sobre o mundo, a sociedade e os homens. Nesse contexto social havia pouca margem a produções teóricas que tomassem como objeto as singularidades e, consequentemente, pensassem a subjetividade.

A passagem das formas de propriedades feudais e comunais para a apropriação privada dos meios de produção que caracterizou a Idade Moderna acarreta a dissolução desses vínculos calcados na tradição, numa hierarquia social preestabelecida e na ordem rígida e divina do mundo. Com isso, projeta-se a categoria de indivíduo e os processos de individualização como ideal e pré-condição para a realização do sujeito no contexto da vida em sociedade. Vida essa agora marcada por relações instrumentais e interesses particulares, em cujo seio "ser alguém pressupõe tornar-se alguém" (Figueiredo, 1991, p. 20).

O Renascimento e a Idade Moderna introduzem mudanças substanciais na visão de homem, de mundo, na construção do saber e do fazer técnico e científico. O ser antes sacralizado, agora é mundano, geometrizado e mensurável. O conhecimento antes muito mais contemplativo agora é ativo, atua sobre e pode transformar a natureza e os homens. Assim, o mundo é visto como um objeto a serviço do homem, passível de intervenção e de exploração. E a Terra, ao deixar de ser considerada o centro do universo, despoja tam- bém o homem da cômoda posição de ser ele conduzido pela mão divina, levando-o, então, a se ver como um ser errante em um espaço que precisa ser desvelado, compreendido e controlado. Antes a fé; agora a razão. Ao se colocar no centro de sua própria vida, dos seus próprios interesses e decisões, o homem moderno descobre sua subjetividade. $\mathrm{O}$ contato com a diversidade impôs novos modos de ser e a construção de individualidades únicas (Figueiredo, 1992). Esse cenário diversificado impõe à ciência a necessidade de um método que discipline a liberdade humana e que fundamente toda a construção do conhecimento. Assim, a partir dos séculos XVI e XVII, a subjetividade e a noção de sujeito, do Eu, vão se constituindo, cada vez mais, como categorias fundamentais no pensamento filosófico, delineando, no decorrer desses séculos e, principalmente, nos seguintes, a gênese da Psicologia como ciência autônoma. Todavia, ainda hoje, seja nas ciências humanas seja na própria Filosofia, de onde essas categorias emergem, não há qualquer consenso explicativo quanto a tais conceitos. No campo específico da Psicologia não poderia ser diferente. $\mathrm{Na}$ ânsia de compreender seu complexo objeto de estudo, o homem, e desde sua instituição como ciência no século XIX, a Psicologia vem permanentemente tecendo considerações e estabelecendo definições a respeito, bem como propondo diferentes métodos de investigação do fenômeno. Todos, no entanto, totalmente divergentes.

De fato, a ciência psicológica hoje se apresenta constituída por várias psicologias, configurada por diferentes abordagens teórico-metodológicas com fundamentos, métodos e conceitos demarcados por fronteiras nem sempre evidentes ou tranquilas. Nesse âmbito, subjetividade, identidade, singularidade, individualidade, personalidade, afetividade, consciência, comportamento ou mesmo sujeito e indivíduo referem-se a pressupostos epistemológicos diferenciados, compreendidos com maior clareza apenas nos cercados teóricos de cada psicologia.

Desse modo, esse artigo analisa o conceito de subjetividade, recuperando as dimensões histórico-filosófica e discursiva da concepção de sujeito e de sua relação com a linguagem, aprofundando-o no campo da psicologia, a partir da psicologia sócio-histórica e da análise institucional do discurso.

\section{Análise epistemológica e conceitual da subjetividade}

Subjetividade consiste num substantivo abstrato, composto pelo radical subjetiv e pelo sufixo idade. Em nossa língua, o sufixo idade é formador de subs- 
tantivos abstratos derivados de adjetivos, significando a qualidade ou característica do que é uma dada coisa, ou seja, definindo algo que corresponde ao adjetivo que lhe serve de base. Por exemplo, realidade indica a qualidade ou característica do que é (de ser) real. A qual adjetivo o substantivo subjetividade corresponde? Não é difícil imaginar que corresponde ao adjetivo subjetivo. Portanto, subjetividade seria a qualidade ou característica do que é subjetivo. Sendo que o adjetivo subjetivo significa: aquilo que é próprio do sujeito ou a ele relativo. Atrelado ao conceito de subjetividade, temos, portanto, os conceitos de subjetivo e sujeito. Percebe-se, além disso, que os termos subjetivo e sujeito estão diretamente relacionados na gênese da palavra subjetividade, sendo sujeito o conceito gerador (sujeito $<=>$ subjetivo $<=>$ subjetividade).

O termo sujeito, do qual derivam os termos subjetivo e subjetividade, embora de uso comum nos discursos da psicologia, requer uma análise de maior complexidade semântica no campo da Filosofia.

De acordo com Sales (2007, pp. 79-92), o termo sujeito, em sua acepção filosófica, já na Filosofia Antiga tanto como na Filosofia Medieval, tinha o sentido de fundamento, substrato, e era aplicado a qualquer substância; não apenas ao homem. É assim que o encontramos em Aristóteles e em São Tomás de Aquino. Para designar o sujeito, o filósofo grego empregou as palavras hypokéimenon (fundamento) e ousía (substância). É dele a afirmação de que "o homem individual não é em nada mais substância que o boi individual". E, a despeito do fato da palavra substância ter aplicações diferentes nos textos de Aristóteles, em todas elas o sentido de fundamento prevalece. Os filósofos medievais conservaram o sentido atribuído por Aristóteles ao sujeito e adotaram para designá-lo as palavras latinas subjectum - aquilo que está por baixo como suporte, fundamento - e substantia - a qualidade de cada coisa, sua essência, aquilo que é o substrato dos acidentes (Sales, 2007). René Descartes (15961626), considerado o inventor do sujeito moderno ou da filosofia da subjetividade, paradoxalmente, lança mão da palavra sujeito em seu sentido filosófico tradicional, isto é, aristotélico-tomista. No entanto, o filosofo francês realiza uma verdadeira guinada filosófica, pois é a partir dele que o homem passa a ser o fundamento último de toda a realidade, de todo o saber. Assim, em Descartes, o homem se torna subjectum, ou seja, o primeiro e real fundamento. Mas que homem? O homem como res cogitans (coisa pensante). E a nova concepção de sujeito que desponta no horizonte filosófico passa a ser sinônimo de subjetividade (Sales, 2007).
Voltemos a nossa língua e analisemos mais de perto o termo em latim referente a sujeito. Subjectum trata-se de uma palavra composta a partir do prefixo $s u b$ (preposição que indica sob, debaixo, sempre exprimindo a ação de estar, colocar debaixo) mais o verbo jactum, jacio, jacere (que indica: lançar-se, arrojar-se) ${ }^{1}$. Portanto, sujeito é aquilo que se lança de baixo, como fundamento, e com isso coloca, funda; lança-se e funda, institui, coloca, sustenta o mundo, o real. Essa é acepção de Descartes para o cogito, o sujeito pensante. É interessante observar os termos objeto e objetivo, palavras contrapostas a sujeito e subjetivo. Objeto (e objetivo) tem por base objectum, objectu que, diferente da palavra subjectum, é composto pelo prefixo $o b$, preposição que significa "a frente a", "diante de" e "por causa de". Portanto, $o b$ jectum, objectu é aquilo que esta a nossa frente e sobre a qual lançamos a nossa vista e a nossa ação. Mas $o b$, às vezes, também significava "sem", "fora de" (obsceno: fora de cena); e ainda "na frente, atrapalhando a passagem". Objeto, portanto, é tudo aquilo externo ao sujeito e sobre o qual, esse sujeito como fundamento, se lança: lança o olhar, o pensamento, a ação.

Que desdobramentos nós teríamos a partir disso para a discussão da subjetividade? Em primeiro lugar, nesse contexto filosófico-epistemológico e conceitual, subjetividade passa a ser entendida como o fundamento do real; algo que vem primeiro, primordial, portanto, essencial. O espaço íntimo e pensante do sujeito, do indivíduo (seu mundo interno), a partir do qual ele se relaciona com (se lança sobre) o mundo objetivo (mundo externo, social e natural), dando-lhe sentido, ou seja, produzindo, fundando, colocando, instaurando o real, o mundo, as coisas. Em segundo lugar, e como decorrência do primeiro, o sujeito e a subjetividade passam a ser entendidos como tendo uma existência a priori, universal e independente do real (e consequentemente, o objeto, a objetividade também). Em terceiro, instaura-se a partir dessa concepção a clássica dicotomia sujeito-objeto, subjetividade-objetividade, interno-externo, psíquico-social etc., a qual dará abertura tanto para visões subjetivistas como objetivistas no campo científico-filosófico que se constitui a partir da modernidade.

Descartes inaugura o Racionalismo ao evidenciar um sujeito como fundamento de todo o conhecimento: o sujeito cognoscente. Diante da incerteza do mundo, há o sujeito que duvida de todo julgamento. A ação de duvidar requer um sujeito e essa ação garante a existência do sujeito que duvida. Assim, o sujeito do co- 
nhecimento é capaz de produzir um conhecimento objetivo do mundo. Busca-se uma verdade primeira que não possa ser posta em dúvida, acentuando-se o caráter absoluto e universal da razão. De Descartes a Kant o sujeito fundamento da tradição filosófica assumirá formas diferenciadas nos chamados paradigmas da modernidade.

Francis Bacon (1561-1626) com a mesma preocupação de Descartes em estabelecer um método para assegurar o conhecimento científico, o procura no campo da experiência subjetiva sensorial, baseada nos sentidos e na percepção. Inaugura-se o Empirismo que, ao contrário do Racionalismo, enfatiza o papel da experiência sensível no processo do conhecimento. Porém, o sujeito empírico é passível de erro e de ilusão. O homem assume uma postura cautelosa para consigo próprio na medida em que são descartadas as ideias a priori, devendo submeter-se a uma disciplina metodológica rigorosa para fazer uma leitura correta e objetiva da realidade.

Muitas abordagens da Psicologia, em maior ou menor grau, com maior ou menor consistência, adotaram elementos dessa concepção de subjetividade e da relação entre subjetividade e objetividade. Ora dando maior ênfase à subjetividade; ora negando-a, diluindoa e afirmando apenas a objetividade; ora enfatizando a chamada interação (interação subjetividade e objetividade). Ou seja, ora entendendo a subjetividade como instância produtora do real, das coisas, do mundo; ora como esfera meramente produzida pelos objetos (naturais e/ou sociais); ora como resultado de uma suposta inter-relação entre subjetividade e objetividade, mundo interno e mundo externo, indivíduo e sociedade, etc. Em todos os casos, mantêm-se subjetividade e objetividade como esferas autônomas, universais e distintas.

A tradição conhecida como cartesiana, embora considerada dominante no campo da psicologia, será confrontada por alguns paradigmas conceituais e teórico-metodológicos informados pela dialética, em sua tradição hegeliana europeia e em seus desdobramentos de vocação crítica. Afastam-se da problemática da substância ou da essência no estudo do sujeito, de sua forma apriorística, questionando sua soberania, esvaziando e despersonificando suas formas personológicas ou essencialista. Segundo Araújo (1998), Hegel (1770-1831) critica os princípios fundamentais da metafísica aristotélica, dentre eles a noção de substância, pois as coisas são em si mesmas contraditórias, o que dispensa o sentido de identidade absoluta, imediatez e consistência. As coisas só são em oposição a outras. O não ser reside no próprio ser. A razão apreende a negação, a contradição, e não os seres em sua essência substancial.

Em algumas abordagens que derivam dessas concepções, um elemento em comum passa a ter relevância: a centralidade ocupada pela linguagem. Desde o final do século XVIII o pensamento ocidental volta-se para o problema da linguagem, desencadeando transformações importantes na filosofia e nas ciências humanas, que irão colocar a linguagem no centro das preocupações teórico-metodológicas e dos processos de produção do conhecimento partir de final do século XIX.

O século XX elege a linguagem como o pano de fundo para o pensamento filosófico contemporâneo, destacando-se inicialmente o problema da referência e do significado (relação palavra-mundo). Esse movimento pressentido por Hegel coloca a linguagem no lugar do puro pensamento e das ideias do racionalismo, no lugar do empirismo do século XVII, bem como no lugar da razão kantiana em suas formas puras e a priori (Araújo, 2004). A linguagem, caracterizada em suas dimensões de signo, de proposição, de ato de fala e de discurso, também se colocará como elemento central para as teorizações do sujeito em algumas perspectivas da Psicologia, com seus referenciais próprios e diversos como a psicanálise e a psicologia sócio-histórica.

Dentre os desdobramentos colocados pela filosofia de Descartes aos diferentes campos de estudos do sujeito, a filosofia da linguagem tem como principal objetivo ou alvo, e ponto de partida, a crítica radical à concepção representacional da linguagem, segundo a qual a linguagem serve à comunicação do mundo das ideias. Do ponto de vista filosófico-epistemológico, quais foram suas principais marcas em relação ao estudo do sujeito, ou da subjetividade?

Com Descartes a filosofia focalizou o mundo mental (res cogitans) de modo a esquadrinhar nossas ideias para que fossem claras e distintas. A linguagem é o meio ou o instrumento de externalização das ideias, pelo qual podemos comunicá-las aos demais. O pensamento é extralinguístico, sendo que a linguagem pode, inclusive, ser a causa de erros e equívocos. Essa concepção fundada no consenso prévio do mundo das ideias institui a primazia da filosofia da consciência, a qual será o principal alvo de enfrentamento da filosofia da linguagem.

Os filósofos Gottlob Frege (1848-1925) e Bertrand Russel (1872-1970) são considerados os fundadores 
da filosofia analítica e os representantes do empirismo lógico; os filósofos do chamado círculo de Viena (conjunto de filósofos reunidos em torno de Moritz Schlick, 1882-1936, dentre eles Ludwig Wittgenstein, 1889-1951) são considerados fundadores do positivismo lógico; os filósofos de Oxford (Gilbert Ryle, 1900-1976; John Austin, 1911-1960; Paul Grice, 1913-1988 e Peter Strawson, 1919-2006) são considerados responsáveis pela sistematização do componente pragmático nos estudos da linguagem, ou seja, pelo seu uso na interação entre sujeitos. Esses filósofos empreenderam esforços para deslocar a relação mente/mundo para linguagem/mundo.

Esse movimento iniciado pela filosofia analítica contribuiu para que a linguagem deixasse seu estatuto de mero veículo de nossas ideias, para tornar-se condição de nosso pensamento, ocupando o lugar da mente que conhece ou representa os objetos. A linguagem é, assim, mais que representação do mundo, pois é basicamente instrumento com o qual se faz coisas, se faz pensamentos, se faz realidades. Ela adquire relevância no estudo da comunicação humana; é ação, é interação, é ato de fala, é jogo de linguagem. É estrutura articulada, independente de uma vontade individual e subjetiva; não se limita a estabelecer uma relação direta com a coisa nomeada.

A virada na relação mente/mundo para linguagem/mundo configura um novo panorama para os diferentes campos de estudo da linguagem, permitindo o surgimento da linguística do signo, do estruturalismo, da semiótica, das análises do discurso. Inúmeras problematizações e soluções serão desencadeadas em diferentes campos de produção do conhecimento, com especial repercussão para as ciências humanas e particularmente para a linguística. A partir dela, ou de uma reação a ela, e das influências da filosofia da linguagem, diferentes teorias discursivas irão buscar a solução para a relação entre realidade e sujeito, passando obrigatoriamente pela linguagem, mais precisamente pela sua dimensão discursiva, ou seja, a dimensão do sentido e de sua relação constitutiva com o sujeito.

Do ponto de vista científico, a chamada virada linguística se coloca à tarefa de resolver o problema da interpretação, em resposta à história da compreensão fenomenológica. A solução encontrada por Ferdinand de Saussure (1857-1913) é eliminar o problema, ou seja, o falante. Saussure produz a divisão entre língua (social) e fala (individual), elegendo o estudo da língua, por meio do método estruturalista, como forma de instituir o estatuto e a autonomia da linguística enquanto ciência. Para isso é preciso colocar-se no plano da língua e tomá-la como norma de todas as outras manifestações da linguagem; essa, multiforme e heteróclita, aquela, homogênea por natureza, constitui-se em um princípio de classificação. A língua é um sistema de signos, os quais unem um conceito a uma imagem acústica (Saussure, 1970). A linguística saussuriana garantiu a várias ciências o estudo da língua enquanto objeto da cultura, instância pública, objetiva e social. Abriu, assim, um novo leque de alternativas para o estudo do sujeito e da subjetividade, agora enquanto produto ou efeito da linguagem.

Temos assim, por um lado, o sujeito soberano que usa a linguagem para externalizar as ideias e atribuir sentido ao mundo; por outro lado, a língua enquanto estrutura sem sujeito, cujo estudo do significado cedia-se ao interior do próprio sistema. Segundo Bakhtin (1986) essa divisão retrata posições teóricas por ele intituladas subjetivismo individualista, e objetivismo abstrato, irreconciliáveis do ponto de vista do estudo significado (social e cultural) e do sentido (subjetivo, individual), com consequências importantes para qualquer teorização sobre o sujeito. A relação entre linguagem e subjetividade deverá, segundo esse filósofo, percorrer outra direção que contemple dialeticamente o problema do signo, sem dicotomizar a relação entre sentido e significado. Esta intuição do autor se confirmará ao longo do século XX enquanto fundamento de várias teorias do discurso.

\section{A relação entre linguagem e sujeito na filosofia de Mikhail Bakhtin}

Mikhail Bakhtin (1895-1975) propõe uma solução própria aos problemas colocados pela filosofia da linguagem e pela linguística, redefinindo a concepção de signo, de língua, de enunciado, de gênero e de sujeito, por meio de uma concepção dialógica e discursiva da linguagem. Enfrenta o problema da filosofia da consciência ou teoria do sujeito por outro caminho.

O signo, segundo Bakhtin (1986) é uma realidade objetiva, que se localiza externamente ao lado dos fenômenos naturais, porém ultrapassa a realidade natural e o caráter funcional dos objetos, podendo representá-los, atribuindo-lhes múltiplos sentidos. Um signo não existe apenas como parte de uma realidade; ele também reflete e retrata outra. Ele é criado por uma função ideológica precisa, que veicula nos sistemas sociais de representação, entre eles a linguagem.

Aqui podemos retratar o que caracteriza a visão social e histórica no pensamento desse autor: ele rompe com as correntes idealistas que situam o mundo da 
cultura na consciência, ao explicar sua existência a partir da consciência individual, sem suporte na realidade social. A consciência só pode surgir e se afirmar como realidade mediante a encarnação material em signos. Imerso nas redes de significação de seu universo simbólico, o sujeito subjetiva-se, e, a partir deste universo, objetiva seu eu na palavra, diferenciandose de outros. (Bakhtin, 1986).

Desse modo, a linguagem verbal não é vista como um sistema formal, mas como atividade, ou seja, como um conjunto de práticas socioculturais que se concretizam em diferentes gêneros do discurso, que por sua vez, concretizam diferentes vozes sociais (posições avaliativas). A atividade socioverbal não se restringe à comunicação face-a-face, ou ao diálogo no sentido restrito do termo, tampouco se restringe à "eventos fortuitos e aleatórios entre mônadas falantes que trocam enunciados a esmo". A atividade socioverbal é compreendida enquanto evento situado num complexo quadro de relações socioculturais, sempre. São as relações dialógicas, entendidas como relações de sentido que decorrem da responsividade (tomada de posição axiológica) inerente a todo e qualquer enunciado, o foco de atenção nessa abordagem (Faraco, 2003, p.106).

A língua constitui-se por uma estratificação infinita que se amplia e se aprofunda de forma dinâmica, revelando sua força viva. É heterogênea em sua natureza, sua base constitutiva é a plurivalência, que retrata diferentes formas de significar a realidade, segundo as vozes, as axiologias dos que a empregam.

A vida social e histórica da linguagem cria formas normativas, as quais são abstraídas de sua realidade viva e concreta e carregam diferentes conteúdos semânticos e axiológicos. Sendo assim, a forma de interpretação dos índices gerais linguísticos abstratos é plurilíngue, e mesmo a língua literária oral e escrita, única, é estratificada. O que determina esta estratificação é a união dos elementos da língua à sua "orientação intencional" e ao "sistema geral de acentuação destes ou daqueles gêneros". Os elementos da língua adquirem, assim, o "perfume específico dos gêneros dados" e "se adéquam aos pontos de vista específicos, às atitudes, às formas de pensamento, às nuanças e às entonações destes gêneros" (Bakhtin, 1988, p. 96).

A estratificação social da linguagem pode coincidir com a estratificação de gêneros e profissões, sem perder sua autonomia e especificidade, o que nos permite entender que cada época histórica tem suas linguagens, mas também as tem uma idade específica (a criança, o adolescente), que pode variar dentro de contextos institucionais distintos (escolas); ou seja, em cada momento de sua existência a linguagem é pluridiscursiva. $\mathrm{O}$ cruzamento desses fatores pressupõe a existência de contradição entre épocas e grupos - as linguagens interceptam-se de diversas maneiras, sem perder, contudo, sua perspectiva semânticoaxiológica: "todas as línguas do plurilinguismo, qualquer que seja o princípio básico de seu isolamento, são pontos de vista específicos sobre o mundo, formas de interpretação verbal" (Bakhtin, 1988, p. 98).

O processo de enunciação representa um ponto de cruzamento de forças, um ponto de tensão entre as forças unificadoras e centralizadoras e as forças de desunificação. "Cada enunciação que participa de uma língua única (das forças centrípetas e das tendências) pertence também, ao mesmo tempo, ao plurilinguismo social e histórico (às forças centrífugas e estratificadoras)." Nesse sentido, o autor define o enunciado, meio onde vive e se forma a língua, como um "plurilinguismo dialogizado, anônimo e social como linguagem, mas concreto, saturado de conteúdo e acentuado como enunciação individual" (Bakhtin, 1988, p. 82).

Com base no plurilinguismo dialogizado, a língua deixa de ser compreendida como um sistema homogêneo, estável e neutro, como um código, para ser pensada enquanto dialogia permanente que permite defini-la como uma arena de vozes situadas em diferentes posições sociais. Nessa concepção plurilíngue e dialógica da linguagem, o falante não é o "Adão mítico que chega com a primeira palavra em um mundo virgem" (Bakhtin, 1988, p. 88; 1992, p. 319), tampouco transita livremente sobre suas formas de significação. $\mathrm{O}$ enunciado, embora único e irrepetível, só é possível a partir do já-dito, sob pena de não ser compreendido. A enunciação é sempre uma réplica do diálogo, inserida na cadeia dialógica (intertextos), na memória social.

Desse modo, o objeto do discurso não é a palavra neutra, mas o discurso do outro (que contém seu ponto de vista, sua visão de mundo). É no enunciado - no texto, no discurso, nas formas vivas de linguagem que se dão os processos de subjetivação. Todo enunciado pressupõe a relação entre o eu e o(s) outro(s), a qual, mostrada ou apagada, sustenta o dialogismo enquanto instância constitutiva da linguagem e configura sua dimensão alteritária. A linguagem é sempre orientada para o outro; é também, uma reposta presumida. Portanto, no lugar da interpretação o autor propõe a compreensão responsiva. Ao enunciar, o sujeito diz algo de uma dada maneira, dirigindo-se a alguém, o que terá interferência na própria maneira de dizer. Assim, o dialogismo, instância constitutiva da lingua- 
gem, institui-se como instância de possível estudo da subjetividade, e desloca qualquer reflexão sobre o sujeito, de uma análise subjetiva individual (subjetivismo individualista nas palavras de Bakhtin, no sentido de recusa a qualquer forma de idealismo ou psicologismo no estudo do sujeito), para a dimensão intersubjetiva e intertextual, interdiscursiva ou dialógica. $\mathrm{O}$ sujeito enuncia num universo de vozes que ao mesmo tempo o posicionam e o descentralizam. Sua ação, no entanto, produzirá efeitos no universo de sentidos, subvertendo-o, transformando-o, e desse modo, significando e re-significando o mundo e a si próprio.

O autor esclarece que a alma social do enunciado vive e morre no processo de interação social. As palavras, os gestos e as entoações não são a expressão de estados mentais dos falantes, mas expressam sua forte e viva relação com o meio social (amigos, inimigos, aliados). O processo de significação é um fenômeno dialógico e social, não um processo cognitivo e individual (conforme pressuposto por Saussure), ou um processo interacional que se configura na interação face a face (conforme os estudos dos atos de fala e da pragmática). Falar não é expressar livremente o pensamento, mas ser capturado por um universo de sentidos produzidos pelas práticas discursivas. Ao enunciar o sujeito age responsivamente nesse universo de sentidos, posiciona-se, a si mesmo em relação ao outro, ou seja, submete-se, aliena-se, ao mesmo tempo em que subverte o sentido do enunciado, recria, ressignifica, tanto a si mesmo quanto ao mundo.

Não produzimos, desse modo, sentidos e significados; mas estamos, sim, sob efeitos de sentidos produzidos e estabilizados pelas práticas sociais; estamos sob efeitos do perfume específico dos gêneros que nos situam e nos posicionam. A ideia de expressão do pensamento é substituída pela questão de como nos posicionamos subjetivamente no discurso, de quando e de como podemos falar ou calar. Se devemos falar ou calar! O discurso delimita justamente o que pode ou não ser dito. A linguagem é, assim, uma atividade social e humana; a língua, enquanto plurivalência, é uma semiose infinita, é a memória cultural, que possibilita ao sujeito, ser humano, tornar-se humano, humanizar-se.

Constatamos desse modo que a linguagem, para alguns pensadores que a elegem como fundamental para as reflexões sobre o sujeito, torna-se um dos principais elementos para a compreensão das relações instrumentais das práticas sociais da modernidade, nas quais ser alguém significa tornar-se alguém. Tornar-se alguém implica a mediação de um universo semiótico que é mais que representação, nomeação, expressão de ideias. É também produção material e simbólica dos modos de existência do sujeito. Ou seja, modos de produção da subjetividade. Cada época, cada sociedade, põe em funcionamento alguns desses modos, elegendo aquele que se torna hegemônico, como é o caso do sujeito moderno, cuja realização, no contexto da vida em sociedade, projeta a categoria de indivíduo e os processos de individualização como ideal para sua realização. Esse sujeito, contudo, vive imaginariamente a ilusão de que é senhor de sua própria vida, vive a ilusão de unidade e plenitude, sem, contudo, reconhecer-se como sendo passível de qualquer controle sobre os modos de produção da vida. Pensadores como Sigmund Freud (1856-1939) e Karl Marx (1818-1883) denunciam a cisão do sujeito; sua alienação.

\section{0 sujeito e a subjetividade na psicologia sócio- histórica}

Como toda e qualquer ciência, a Psicologia é um produto histórico-social, resultado da atividade prática humana que se volta sobre a materialidade natural e/ou social do mundo. Seus conhecimentos referemse, portanto, às determinadas abstrações (apropriações) de seu objeto, isto é, do fenômeno psicológico, realizadas, por sua vez, a partir de determinadas concepções de homem, de mundo e do próprio conhecimento que são, elas também, fundadas num dado tempo e lugar e, por outro lado, o fundamento para os métodos e para as técnicas pelas quais se investiga esse objeto e se produz um saber e um fazer a seu respeito.

Na perspectiva marxista, isto é, baseada no materialismo histórico e dialético, buscar-se-á justamente romper com o universalismo essencialista e o determinismo mecanicista e dualista, presente na separação interno-externo, psíquico-social, bem como com o idealismo abstrato e metafísico subjacente aos pressupostos que comumente impregnam o termo subjetividade no campo da Psicologia. Para isso, a Psicologia Sócio-histórica buscará na concepção marxista de homem os fundamentos para o entendimento da subjetividade.

Assim, subjetividade passa a ser entendida a partir da relação singular-particular-universal, compreendendo tal fenômeno como unidade do diverso, síntese de múltiplas determinações. O que implica abordar a subjetividade como processo e como fenômeno ontologicamente indissociável da intersubjetividade, isto é, da relação dos homens com outros homens. Portanto, 
como conjunto de relações históricas e sociais (Saviani, 2004). E, por outro lado, no seio das relações sociais vigentes, como fenômeno diretamente relacionado aos (fundado sobre) processos de alienação. O que determina, por sua vez, uma dada concepção do que seja fazer ciência a respeito da subjetividade. Vejamos.

Segundo Duarte (1993), o processo de constituição da subjetividade ou da individualidade, como o autor se refere, se dá em razão da apropriação pelo indivíduo singular da cultura humana, isto é, dos produtos materiais e simbólicos da atividade histórica e social dos homens, acumulados de forma objetiva ao longo da história. Em outras palavras, a formação da subjetividade realiza-se a partir da apropriação das objetivações que compõem o gênero humano - objetivações genéricas - num dado momento histórico.

O que seriam, de fato, essas objetivações? Seriam tudo aquilo que se constitui como resultado da atividade social humana e que, por isso, encarna de forma objetiva, exterior ao homem, o ser do homem, sua humanidade, sua genericidade ${ }^{3}$. Ou seja, suas forças essenciais historicamente produzidas, suas faculdades, capacidades e aptidões, tanto físicas como psíquicas, as quais, dado o seu caráter objetivo, são transmissíveis de uma geração a outra.

Como síntese das forças essenciais humanas, as objetivações condensam em si uma determinada atividade social humana historicamente desenvolvida que pode ser tanto objetiva quanto subjetiva. Nesse sentido, constituem-se nos elementos mediadores entre a genericidade (o gênero humano) e o indivíduo concreto que delas se apropria, tornando-as parte constitutiva do seu ser particular. Todos os elementos de nossa cultura sejam eles materiais ou simbólicos, objetos ou comportamentos, consistem em objetivações genéricas. E o homem só se torna humano quando se apropria desses elementos. Por sua vez, as relações que os homens estabelecem com essas objetivações fazem a mediação das relações que eles estabelecem com o mundo, isto é, constituem-se nos instrumentos que guiam os homens no interior da realidade produzida pela humanidade. Poderíamos dar como exemplos de objetivações genéricas os utensílios e instrumentos de nossa cultura - objetivação material - e a linguagem objetivação simbólica. Enfim, toda objetivação é potencialmente objeto de uma apropriação e o indivíduo tem necessariamente que se apropriar dessas objetivações, ao longo de seu processo de formação, para poder constituir-se como ser humano e existir no mundo criado, objetivado, pelos homens (Duarte, 1993). Por isso o homem é um ser essencialmente social, ou seja, porque o objeto de suas apropriações, que o constitui como humano, é social.

Além disso, a apropriação dessas objetivações faz, por sua vez, a mediação dos próprios processos de objetivação, isto é, dos processos de produção e reprodução dessa mesma cultura. Pelos processos de apropriação, o indivíduo torna seu, transforma em parte de seu ser, aquilo que foi produzido (objetivado) por outros indivíduos ao longo da história, produzindo assim, ao mesmo tempo, as condições objetivas e subjetivas em cujo interior se dará os processos de formação das próximas gerações e dos indivíduos ao ser redor. É na relação entre os processos de objetivação e apropriação que o indivíduo se autoproduz e se reproduz, ao mesmo tempo produzindo e reproduzindo, portanto, a própria cultura humana, tanto na sua dimensão material quanto simbólica. Isto significa que os processos de objetivação e apropriação se constituem na mola propulsora tanto do desenvolvimento sócio-histórico da subjetividade, quanto do desenvolvimento da sociedade, do gênero humano.

Tais processos, por sua vez, não podem realizar-se sem a mediação de outros indivíduos. Ou seja, sem a participação do próprio homem, de um indivíduo que transmita, direta ou indiretamente, o significado humano contido nos elementos de nossa cultura. Daí Leontiev (1978) ter afirmado que não existe apropriação que não seja mediada por um outro indivíduo e que, portanto, não se constitua num processo educativo, no sentido lato do termo. Em outras palavras, não há subjetividade fora dos processos intersubjetivos, isto é, à parte de processos educativos.

Estritamente no campo da Psicologia, essa concepção acerca do homem recolocará o indivíduo, o sujeito e a subjetividade como produções histórico-sociais, a partir da sua relação dialética com a objetividade. Conforme afirma Gonçalves (2001, p. 50):

A Psicologia Sócio-Histórica vai propor a partir de Vigotski, que estudem os fenômenos psicológicos como resultado de um processo de constituição social do indivíduo, em que o plano intersubjetivo, das relações, é convertido, no processo de desenvolvimento, em um plano intra-subjetivo. Assim, a subjetividade é constituída através de mediações sociais. Dentre essas mediações, a linguagem é a que melhor representa a síntese entre objetividade e subjetividade. Isso porque o signo é, ao mesmo tempo, produto social que designa a realidade objetiva; construção subjetiva compartilhada por diferentes indivíduos através da atribuição de significados; e construção subjetiva individual, que se dá através do processo de apropriação do significado social e da atribuição de sentidos pessoais. 
No campo da Psicologia Sócio-histórica, portanto, a linguagem consiste fenômeno privilegiado no que se refere às possibilidades de acesso ao psiquismo humano, ao campo do afetivo-volitivo, do pensamento, dos significados e dos sentidos.

Por outro lado, a dinâmica entre os processos de apropriação e objetivação, de conversão do intersubjetivo em intrassubjetivo (e vice-versa), que constituem tanto a individualidade como a cultura humana não se dão no vazio, abstratamente, mas sempre pela mediação de uma dada sociedade: o polo da particularidade. Assim, a apropriação por todo e qualquer indivíduo (o polo da singularidade) da genericidade humana (o polo da universalidade) se dá sempre no seio de relações sociais concretas, isto é, no interior de uma dada sociedade marcada por determinadas relações sociais (o polo da particularidade). Embora essas relações possam determinar tanto processos de humanização, isto é, relações que coloquem aos indivíduos possibilidades concretas para que se efetive seu pleno desenvolvimento humano - cognitivo, afetivo, estético, político, moral etc. - em nossa sociedade esses processos se dão no interior de relações marcadas essencialmente pela alienação. Como define Mészáros (2006): alienação da natureza; alienação de si mesmo; alienação do gênero humano (da genericidade); alienação dos próprios homens. E isso num duplo aspecto: objetivo e subjetivo, material e espiritual.

Conforme define Saviani (2004, p. 29), alienação deriva etimologicamente do adjetivo latino alius que significa "outro". Alienação pode, então, significar tanto "tornar outro" ou "tornado outro" como "tomado por outro", "passado para outro". Em todos os casos, significando ruptura, distanciamento, separação. Na perspectiva marxista, alienação tem um caráter sempre essencialmente negativo e se refere ao afastamento do homem, por meio de barreiras socialmente impostas, dos produtos de sua atividade (objetivações), da riqueza material e espiritual historicamente produzida pelo conjunto dos homens (afastamento do gênero humano). O que impõe a esses indivíduos condições de alienação tanto das riquezas materiais produzidas pela humanidade como de determinadas capacidades espirituais, estéticas, cognitivas e morais desenvolvidas pelo homem ao longo da história e necessárias para a superação das condições históricas e sociais que produzem o próprio fenômeno da alienação. Duarte (2000) refere-se a esse fenômeno de alienação como um processo de esvaziamento da individualidade (subjetividade) humana.
O problema da subjetividade, colocado a partir desses pressupostos, suscita uma questão para a Psicologia de ordem imediatamente metodológica: como fazer ciência da subjetividade? Se a subjetividade se constitui como conjunto de relações sociais, como síntese de múltiplas determinações, como singularização do universal pela mediação do particular, o que isso implica em temos das pesquisas no campo da subjetividade?

Numa perspectiva marxista, considerando-se o método materialista histórico-dialético, cabe a Psicologia a reconstrução, no plano do pensamento, da teia de relações sociais concretas que produzem o seu objeto. Assim, compete à Psicologia a tarefa de, em suas pesquisas, superar a esfera da representação, romper com o indivíduo empírico, ou seja, aquele que se apresenta imediatamente ao campo de nossa percepção sensível, de nossos sentidos, de nossa intuição, apenas em sua aparência imediata, como um fragmento, um recorte, uma representação, uma abstração. Pois nossa percepção imediata, nossos sentidos e nossa intuição não são capazes de abarcar a totalidade complexa e dinâmica que constitui os fenômenos. O empírico, como aparência e representação, não esgota o nosso objeto. Cabe à Psicologia, isto sim, ir à busca do indivíduo concreto, síntese de múltiplas relações e mediações, no caso, histórico-sociais. O que somente é possível pela reconstrução do real por meio do pensamento conceitual. No entanto, produzindo um saber e um fazer científico que não se limite apenas a compreender o homem, seu objeto, mas sim que crie objetivamente as condições para sua emancipação, que transforme o real a nossa volta.

\section{0 sujeito psíquico da análise institucional do discurso}

Nas palavras de sua fundadora, a psicanalista Marlene Guirado, a análise institucional do discurso constitui uma estratégia do pensamento que se organiza em torno de alguns conceitos (Guirado, 2007). Produzida na interlocução com diferentes campos do saber - a psicanálise, a Análise do Discurso (AD) da escola francesa, a sociologia das instituições concretas e a arqueogenealogia foucaultiana - tal estratégia, como nas demais perspectivas abordadas no presente artigo, entende a subjetividade como produto de uma dada configuração sócio-histórica, ou mais precisamente, de uma dada formação discursiva (Foucault, 2000) ${ }^{4}$. Assim, nesse modo específico de pensar, irá se conceber um sujeito com "sede estabelecida no discurso, sempre" (Guirado, 1995), o que, porém, não o reduz a 
uma "função enunciativa" (Foucault, 2000a) ou a uma "posição no discurso" (Maingueneau, 1997). Como se verá adiante, para Guirado, trata-se de um sujeitoposição, ao qual se pode atribuir a condição de psíquico. Tal proposição sustenta-se na demarcação de algumas diferenças em relação aos pensadores tomados como referência em sua leitura, e no modo singular com que Guirado articula a relação sujeito - discurso - instituição.

Com base na sociologia das instituições concretas (Albuquerque, 1978; 1980), o conceito de instituição é pensado como o conjunto de práticas e relações sociais que, pela ação concreta de seus atores, repete-se e assim legitima-se. Vista deste modo, longe de configurar um ideário, imposto a partir "de fora" ou, como se costuma supor, "de cima" dos sujeitos, uma instituição só se faz nas relações (concretas, imaginárias e simbólicas) que esses atores estabelecem entre si e com o seu fazer. Tais relações - definidas, ao modo foucaultiano, como relações de poder/saber (Dreyfus \& Rabinow, 1995) - são encenadas e legitimadas no discurso através de um jogo contínuo de efeitos de reconhecimento e de desconhecimento (Guirado, 2004). Tomem-se, por exemplo, os discursos produzidos na escola sobre a tão conhecida figura do alunoproblema. Geralmente associada à condição de falta (de requisitos cognitivos ou emocionais) passa a ser creditada como natural e imutável, desconhecendo-se sua condição instituída (as relações sociais em que tal problema e lugar subjetivo se engendram) e, portanto, sua relatividade. Perpetuam-se, assim, expectativas e imagens (de si, do outro e das práticas instituídas) as quais, reconhecidas como tendo sido sempre assim, serão imaginadas como tendo de ser assim, sempre. Neste movimento, credita-se à subjetividade algo da ordem da imanência e da interioridade, desconhecendo-se, como condição de sua produção, a ordem discursiva.

$\mathrm{Na}$ análise institucional do discurso não há, pois, como conceber a relação instituição - sujeito como interação parte-extraparte (Guirado, 2007). Trata-se, antes, de uma relação constitutiva que se produz pela via discursiva - o discurso sendo entendido como cena enunciativa (Maingueneau, 1997), como acontecimento, campo de correlação de forças, espaço de lutas, ocupação e subversão de lugares e de expectativas (Foucault, 2000b). Tal concepção permite a Guirado (1987) formular o conceito de sujeito suporte da ação e do discurso institucional. Reconhecê-lo como suporte, em sua condição de efeito - e não causa - do discurso, não anula, porém, a possibilidade de credi- tar-lhe uma singularidade e de pensá-lo como sujeitoposição: posição esta a ser configurada no interior do discurso, no lugar ocupado no movimento de construção/reconstrução/desconstrução dos sentidos produzidos nas redes discursivas que suportam o fazer institucional. Tampouco inviabiliza a noção de uma realidade psíquica, desde que por "psíquico" entenda-se o modo singular com que esse sujeito se insere no universo de determinadas práticas instituídas e a forma particular como organiza e reedita, no discurso, sua história de relações, os lugares atribuídos, a si e aos outros, e os vínculos concebidos como possíveis nessas relações (Guirado, 1995).

A condição de psíquico atribuída a esse sujeito organizador de sentidos não deveria confundi-lo, todavia, com o sujeito dos afetos de Freud. Evidentemente, não se trata de excluir a dimensão dos afetos, apenas de re-situar o âmbito de sua produção como sendo o discursivo e não, o de uma interioridade psíquica que se contraporia a um discurso supostamente exterior. Sua condição de sujeito-posição também não deveria ser equiparada à noção de sujeito efeito de significante de Lacan, pois, na leitura institucional, não se trata de pensar o assujeitamento como se dando em relação a uma convenção significante supraindividual (o $\mathrm{Ou}-$ tro) ${ }^{5}$ e sim, de situá-lo (a esse modo de sujeição) em relação às práticas institucionais concretas, nas quais o sujeito se faz e se refaz, ao mesmo tempo em que as faz e refaz.

Tomá-lo no modo singular de sua inserção, implica, portanto, assumi-lo como um sujeito que, a seu modo, irá marcar sua posição, organizando sentidos, estilos de pensar, perceber e falar que se repetem - ou se reinventam - ao longo das relações concretas constitutivas de sua história e de si próprio como sujeito. Deste modo, a possibilidade de singularidade no discurso pode ser pensada tanto em sua dimensão de legitimação, quanto como ponto de fuga, de resistência, aos modos de subjetivação na ordem do discurso. Disto deriva a proposição, fundamentada na "regra do duplo condicionamento" entre as estratégias globais e locais (Foucault, 1999) ${ }^{6}$, de que, mesmo assujeitadas a uma formação social que lhes antecede, as práticas sociais não se limitam a espelhá-la, mas, através de seus micropoderes, também a produzem. Assim, os atores institucionais não apenas repetem o discurso da instituição ou refletem, pura e simplesmente, o que ela pensa e sim, organizam, normatizam, regulam, legitimam, rompem - práticas e lugares subjetivos- e, com isto, fazem a instituição. 
Nesse sentido, em que pesem algumas diferenças, Guirado aproxima-se de Foucault ao conceber a tensão estabelecida entre os polos sujeição e resistência implicados nos processos de produção de subjetividade. Ambos os pensadores renunciam a polarizações do tipo práticas de dominação e assujeitamento de um lado, e práticas de libertação e resistência de outro: qualquer prática será sempre condição de sujeição e de resistência (Valore, 2007).

É preciso, pois, pensar num conceito "dobradiça" de sujeito (Guirado, 1995), o qual permite movimentar as singularidades discursivas, ao mesmo tempo em que se reconhecem suas condições institucionais de produção. Como afirma Ribeiro (2007), ao propor o acionamento do sujeito dobradiça, a análise institucional do discurso "imprime contornos à subjetividade e possibilita uma escuta de um 'falar de si', entendendose esse 'si' como 'efeito de subjetivação' numa concepção foucaultiana" (p. 258). Tal escuta, entretanto, não será neutra: o analista não se encontra fora da ordem discursiva que se propõe a investigar, suas expectativas e os sentidos que atribui a esse falar também fazem parte da análise (Guirado, 2000).

Fazendo um paralelo com Silva (2001), ao abordar a perspectiva foucaultiana, pode-se dizer: também na leitura institucional não há como pensar numa subjetividade fora das relações de poder que atravessam o discurso. Todavia, como observou Foucault (1999, p. 96), o discurso pode ser, ao mesmo tempo "instrumento e efeito de poder, e também obstáculo, escora, ponto de resistência e ponto de partida de uma estratégia oposta". Tal perspectiva, ao ser assumida por Guirado (1987), como uma análise do discurso que se propõe a estabelecer "um corte que faz pensar", incentiva o "continuar olhando ou refletindo" (Foucault, 2001) em direção a uma ética em nosso modo de fazer a instituição Psicologia nas diferentes práticas sociais.

\section{CONSIDERAÇÕES FINAIS}

$\mathrm{O}$ conceito de subjetividade aqui analisado em suas dimensões histórico-filosóficas, debatido no campo de estudos da linguagem, aprofundado a partir da psicologia sócio-histórica e da análise institucional do discurso, guardadas suas divergências teórico-metodológicas, nos permite afirmar a existência de um elemento comum fundamental: o entendimento da subjetividade como sendo, simultaneamente, produzida por e (re)produtora de relações históricas e sociais, ou seja, de processos educativos (formativos) datados e situados, cujas especificidades, no seio da sociedade capitalista contemporânea, configuram processos sociais contraditórios que, assim, determinam processos objetivos e subjetivos de assujeitamento-resistência ou, em outras palavras, de alienação-emancipação.

A guinada do sentido aristotélico-tomista de sujeito e sua radicalização para uma filosofia da consciência com Descartes, segundo a qual o sujeito é fundamento último de toda a realidade e de todo o saber, torna-se dominante na modernidade. O sujeito (espaço íntimo, interno e pensante) é entendido como aquele que funda, instaura e dá sentido ao real, possuindo, assim, uma existência a priori, universal e independente da realidade objetiva. A análise filosófica e científica da linguagem retrata o rompimento com a concepção representacional, caudatária da perspectiva cartesiana, para tratá-la enquanto instância constitutiva do sujeito, ressaltando assim sua dimensão discursiva, por meio da qual se pode depreender a relação entre sentido e sujeito. É o que nos permite pensar o sujeito na cadeia histórica ou dialógica e intertextual ou discursiva da linguagem.

A análise dos enunciados, unidade concreta da língua, síntese dos processos de objetivação e subjetivação material, simbólica e imaginária, nos possibilita depreender os processos de subjetivação, os modos pelos quais o sujeito, sob efeitos de sentidos, subjetivase (aliena-se, assujeita-se), ao mesmo tempo em que atua nos processos de transformação e produção de sentidos (resiste, subverte, posiciona-se, emancipa-se).

\section{REFERÊNCIAS}

Albuquerque, J. G. (1978). Metáforas da desordem: O contexto social da desordem mental. Rio de Janeiro: Paz e Terra.

Albuquerque, J. G. (1980). Instituição e poder. Rio de Janeiro: Graal.

Araújo, I. L. (1998). Introdução à filosofia da ciência. Curitiba: UFPR.

Araújo, I. L. (2004). Do signo ao discurso: Introdução à filosofia da linguagem. São Paulo: Parábola.

Bakhtin, M. M., \& Volochinov, V. N. (1986). Marxismo e filosofia da linguagem: Problemas fundamentais do método sociológico na ciência da linguagem (M. Lahud \& Y. F. Vieira, Trad.), São Paulo: Hucitec. (Original publicado em 1929)

Bakhtin, M. M. (1988). Questões de literatura e de estética. A teoria do romance (A. F. Bernadini e cols., Trad.). São Paulo: Hucitec. (Original publicado em 1975)

Bakhtin, M. M. (1992). Estética da criação verbal (M. E. G. G. Pereira, Trad.). São Paulo: Martins Fontes. (Original publicado em 1979)

Dreyfus, H., \& Rabinow, P. (1995). Michel Foucault, uma trajetória filosófica: Para além do estruturalismo e da hermenêutica. Rio de Janeiro: Forense Universitária. 
Duarte, N. (1993). A individualidade para-si: Contribuição a uma teoria histórico social da formação do indivíduo. Campinas: Autores Associados.

Duarte, N. (2000). Vigotski e o “aprender a aprender": Crítica às apropriações neoliberais e pós-modernas da teoria vigotskiana. Campinas: Autores Associados.

Faraco, C. A. (2003) Linguagem e diálogo: As ideias linguísticas do círculo de Bakhtin. Curitiba: Criar Edições.

Figueiredo, L. C. M. (1991). Matrizes do pensamento psicológico. Petrópolis: Vozes.

Figueiredo, L. C. M. (1992). A invenção do psicológico: Quatro séculos de subjetivação. São Paulo: EDUC/Escuta.

Foucault, M. (1999). História da sexualidade (M. T. C. Albuquerque e J. A. G. Albuquerque, Trad.). Rio de Janeiro: Graal. (Original publicado em 1988)

Foucault, M. (2000a). A arqueologia do saber (L. F. B. Neves, Trad.) Rio de Janeiro: Forense Universitária. (Original publicado em 1969)

Foucault, M. (2000b). A ordem do discurso (L. F. A. Sampaio, Trad.) São Paulo: Loyola. (Original publicado em 1970)

Foucault, M. (2001). História da sexualidade (M. T. C. e J. A. G. Albuquerque, Trad.). Rio de Janeiro: Graal. (Original publicado em 1984)

Gonçalves, M. G. M. (2001). A psicologia como ciência do sujeito e da subjetividade: A historicidade como noção básica. Em A. M. Bock, M. G. M.

Gonçalves \& O. Furtado (Orgs.), Psicologia sócio-histórica: Uma perspectiva crítica em psicologia (pp. 37-52). São Paulo: Cortez.

Guirado, M. (1987). Psicologia institucional. São Paulo: EPU

Guirado, M. (1995). Psicanálise e análise do discurso. São Paulo: Summus

Guirado, M. (2000). A clínica psicanalítica na sombra do discurso: Diálogos com Dominique Maingueneau. São Paulo: Casa do Psicólogo
Guirado, M. (2004). Instituição e relações afetivas: $O$ vínculo com $o$ abandono. São Paulo: Casa do Psicólogo.

Guirado, M. (2007). Prefácio. Em M. Guirado \& R. Lerner. (Orgs.), Psicologia, pesquisa e clínica: Por uma análise institucional do discurso (pp. 9-19). São Paulo: FAPESP / Annablume.

Leontiev, A. (1978). O desenvolvimento do psiquismo (M. D. Duarte, Trad.). Lisboa: Horizonte Universitário.

Maingueneau, D. (1997). Novas tendências em análise do discurso. (F. Indursky, Trad.). Campinas: Pontes. (Original publicado em 1987)

Mészáros, I. (2006). A teoria da alienação em Marx (I. Tavares, Trad.) São Paulo: Boitempo. (Original publicado em 1970)

Ribeiro, C. R. (2007). Sujeito-dobradiça: Metáfora de subjetividade, metonímia institucional. Em M. Guirado \& R. Lerner (Orgs.), Psicologia, pesquisa e clínica: Por uma análise institucional do discurso (pp. 245-262). São Paulo: FAPESP/ Annablume

Sales, B. A. (2007). A polissemia do sujeito cartesiano. Princípios, 14, 79-92.

Saussure, F. (1970). Curso de linguística geral (A. Chelini, J. P. Paes \& I. Blikstein, Trad.) São Paulo: Cultrix. (Original publicado em 1915)

Saviani, D. (2004). Perspectiva marxiana do problema subjetividade intersubjetividade. Em N. Duarte, (Org.), Crítica ao fetichismo da individualidade (pp. 21-45). Campinas: Autores Associados.

Silva, M. (2001). Subjetividades no pensamento de Michel Foucault. Dissertação de mestrado não-publicada, Pontifícia Universidade Católica de São Paulo.

Valore, L. A. (2007). Dos modos de subjetivação em Foucault ao sujeito psíquico da análise institucional do discurso: Algumas articulações. Em M. Guirado \& R. Lerner (Orgs.), Psicologia, pesquisa e clínica: Por uma análise institucional do discurso (pp. 223-244). São Paulo: FAPESP/Annablume.

\section{Notas:}

1 Subjetivo, na qualidade daquilo que é próprio do sujeito, advém do latim subjectivu.

2 No Brasil, a denominação Psicologia Sócio-histórica tem sido adotada alternativamente a designação Psicologia Histórico-cultural. No entanto, essas designações referem-se a uma única abordagem da Psicologia fundada no materialismo histórico-dialético de K. Marx.

3 Ou seja, os produtos da atividade objetivadora humana, lembrando que o trabalho constitui-se, nessa perspectiva, na atividade objetivadora fundamental dos homens, no que se refere à constituição da sua humanidade.

4 "Um conjunto de regras anônimas, históricas, sempre determinadas no tempo e no espaço, que definiram, em uma época dada e para uma área social, econômica e geográfica ou lingüística, as condições de exercício da função enunciativa." (Foucault, 2000a, p. 136)

5 Embora esta noção lacaniana permita aproximações com a noção de dispersão do sujeito da $\mathrm{AD}$, ambas não se identificam. A este propósito, pode-se consultar Guirado (1995).

6 Segundo esta regra, "Nenhum 'foco local', nenhum 'esquema' de transformação poderia funcionar se, através de uma série de encadeamentos sucessivos, não se inserisse, no final das contas, em uma estratégia global. E, inversamente, nenhuma estratégia poderia proporcionar efeitos globais a não ser apoiada em relações precisas e tênues que lhes servissem, não de aplicação e conseqüência, mas de suporte e ponto de fixação." (Foucault, 1999, p. 95) 


\section{Sobre os autores:}

Miriam Aparecida Graciano de Souza Pan - Psicóloga e fonoaudióloga, Mestre e Doutora em Letras pela Universidade Federal do Paraná. Professora do Departamento de Psicologia da Universidade Federal do Paraná.

João Henrique Rossler - Psicólogo, Doutor em Educação Escolar pela Universidade Estadual Paulista Júlio de Mesquita Filho. Professor do Departamento de Psicologia da Universidade Federal do Paraná.

Norma da Luz Ferrarini - Psicóloga, Mestre em Psicologia Social e da Personalidade pela Fundação Getúlio Vargas/RJ e Doutora em Educação pela Universidade Federal do Paraná. Professora do Departamento de Psicologia da Universidade Federal do Paraná.

Luciana Albanesse Valore - Psicóloga, Mestre em Psicologia Social pela Universidade de São Paulo e Doutora em Psicologia Escolar e do Desenvolvimento Humano pela Universidade de São Paulo. Professora do Departamento de Psicologia da Universidade Federal do Paraná.

Sidney Nilton de Oliveira - Psicólogo, Mestre em Metodologia da Comunicação Social pela Universidade Metodista de São Paulo, Doutor em Psicologia Social e do Trabalho pela Universidade de São Paulo, pós-doutorado em Economia da Educação pela Universidade de São Paulo.

Endereço eletrônico: miriamagspan@yahoo.com.br 